\title{
Mathematical Modeling of the Early Stage of Clogging of the SEN During Continuous Casting of Ti-ULC Steel
}

\author{
HADI BARATI, MENGHUAI WU, SUSANNE MICHELIC, SERGIU ILIE, \\ ABDELLAH KHARICHA, ANDREAS LUDWIG, and YOUN-BAE KANG
}

\begin{abstract}
The clogging of the submerged entry nozzle (SEN) during the continuous casting of steel can be divided into two stages: the "early stage," when the initial layer of the clog covers the SEN refractory surface owing to chemical reactions, and the "late stage," when the clog layer continues to grow because of the deposition of non-metallic inclusions (NMIs). In this paper, a mathematical formulation is proposed for the build-up of the initial oxide. The chemical reaction mechanism is based on the work of Lee and Kang (Lee et al. in ISIJ Int 58:1257-1266, 2018): a reaction among SEN refractory constituents produces CO gas, which can re-oxidize the steel melt and consequently form an oxide layer on the SEN surface. The proposed formulation was further incorporated as a sub-model in a transient clogging model, which was previously developed by the current authors to track the late stage of clogging. The thermodynamics and kinetics of $\mathrm{CO}$ production, depending on the local pressure and temperature, must be considered for the sub-model of early-stage clogging. Test simulations based on a section of an actual industrial SEN were conducted, and it was verified that the clogging phenomenon is related to the SEN refractory, the chemical reaction with the steel melt, the local temperature and pressure, and the transport of NMIs by the turbulent melt flow in the SEN. The model was qualitatively validated through laboratory experiments. The uncertainty of some parameters that govern the reaction kinetics and permeability of the oxide layer is discussed.
\end{abstract}

https://doi.org/10.1007/s11663-021-02336-x

(C) The Author(s) 2021

\section{INTRODUCTION}

Clogging of the submerged entry nozzle (SEN) during the continuous casting of steel refers to the build-up of solid materials on the inner wall of the SEN. Severe SEN clogging disturbs the melt flow, leads to an

HADI BARATI is with the Chair for Modeling and Simulation of Metallurgical Processes, Department of Metallurgy, Montanuniversitaet, Franz-Josef Street 18, 8700 Leoben, Austria and also with the K1-MET, Franz-Josef Street 18, 8700 Leoben, Austria. MENGHUAI WU, ABDELLAH KHARICHA, and ANDREAS LUDWIG are with the Chair for Modeling and Simulation of Metallurgical Processes, Department of Metallurgy, Montanuniversitaet. Contact e-mail: menghuai.wu@unileoben.ac.at SUSANNE MICHELIC is with the Chair of Ferrous Metallurgy, Department of Metallurgy, Montanuniversitaet, Franz-Josef Street 18, 8700 Leoben, Austria SERGIU ILIE is with the voestalpine Stahl $\mathrm{GmbH}$, voestalpine-Straße 3, 4020 Linz, Austria. YOUN-BAE KANG is with the Graduate Institute of Ferrous and Energy Materials Technology, Pohang University of Science and Technology, 77 Cheongamro, Namgu, Pohang, Kyungbuk 37673, Republic of Korea.

Manuscript submitted 15 June 2021; accepted 19 September 2021.

Article published online October 20, 2021. abnormal temperature distribution and slag entrainment in the mold region, and even disrupts the casting process (blockage of the flow in the SEN), causing additional operational costs. Ti-treated ultra-low carbon (Ti-ULC) steel is widely used in the automobile industry, ${ }^{[1]}$ but the casting of such steel is more sensitive to SEN clogging. ${ }^{[2-4]}$ Metallographic analysis of an as-clogged SEN that was used for casting Ti-ULC steel showed that the clog structure/material contained alumina clusters, a Ti-containing oxide, and frozen steel. ${ }^{[4,5]}$ For comparison, the clog structure/material in an as-clogged SEN that was used for casting Ti-free ULC steel contained mainly pure alumina networks. ${ }^{[6]}$ There are several explanations for the higher clogging tendency in the casting of Ti-ULC steel: the lower surface tension of the melt due to the addition of $\mathrm{Ti}^{[7,8]}$ the higher wettability of the complex oxide formed by local re-oxidation, ${ }^{[9]}$ the interfacial reaction between the SEN refractory and melt, ${ }^{[10]}$ and the smaller size (diameter less than $10 \mu \mathrm{m}$ ) and higher number density of non-metallic inclusions (NMIs). ${ }^{[1]}$ 
Previous studies have generally confirmed that SEN clogging is either correlated to chemical reactions between the steel melt and the SEN refractory ${ }^{[2,12]}$ or to the deposition of suspended NMIs on the SEN wall. ${ }^{[9,13,14]}$ The clogging sequence can be divided into two stages: the "early stage," when the initial layer of the clog covers the SEN refractory surface, and the "late stage," when the clog layer continues to grow. The former is most likely related to the chemical reactions between the steel melt and the SEN refractory, while the latter is related to the deposition of suspended NMIs on the clog front.

The current authors previously proposed a transient clogging model that considers clog growth due to NMI deposition, i.e., the late stage of clogging. ${ }^{[15,16]}$ The model was evaluated against a laboratory experiment, ${ }^{[17]}$ and its accuracy and efficiency were examined for industry-scale SENs. ${ }^{[18]}$ The model was also successfully used to study the role of steel solidification in SEN clogging. ${ }^{[19]}$ However, the chemical reactions between the steel melt and the SEN refractory during the early stage of clogging were oversimplified. The early stage of clogging, i.e., the formation of the initial layer of the clog, was treated numerically by the enhancement of wall roughness due to particle deposition. In the current study, the early stage is re-defined as the reaction between the SEN refractory and melt, which results in the production of an oxide layer on the SEN wall as the initial layer.

Based on a series of experimental and thermodynamic investigations, Lee and Kang ${ }^{[10,20-23]}$ proposed a mechanism for the formation of the initial oxide layer on the SEN wall during the continuous casting of Ti-ULC steel. As shown schematically in Figure 1, multiple reaction steps occur. $\mathrm{CO}$ gas is released because of a chemical reaction between refractory constituents at the elevated temperature of casting (step (1)).

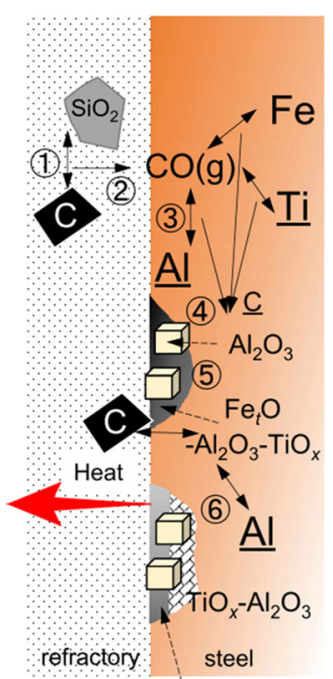

Fe reduced

\section{Proposed mechanism for Ti-ULC} clogging

(1) $\mathrm{SiO}_{2}$ and $\mathrm{C}$ in refractory react to form $\mathrm{CO}(\mathrm{g})$.

(2) $\mathrm{CO}(\mathrm{g})$ moves through refractory pore.

(3) $\mathrm{CO}$ (g) oxidizes $\mathrm{Al} / \mathrm{Ti} / \mathrm{Fe}$ simultaneously.

(4) $\mathrm{Fe}_{t} \mathrm{O}-\mathrm{Al}_{2} \mathrm{O}_{3}-\mathrm{TiO}_{x}(l)+\mathrm{Al}_{2} \mathrm{O}_{3}(\mathrm{~s})$ form and attach to the inner wall.

(5) The liquid oxide containing $\mathrm{Fe}_{t} \mathrm{O}$ works as a binder to refractory/inclusion/liquid steel.

(6) $\mathrm{FeO}$ is gradually reduced by $\mathrm{Al}$ in liquid steel or $\mathrm{C}$ in refractory, forming reduced $\mathrm{Fe}$ and $\mathrm{TiO}_{x}$ $\mathrm{Al}_{2} \mathrm{O}_{3}$.

Fig. 1-Schematic description of the early state of the clogging mechanism. ${ }^{[10]}$ Reprinted with permission from Iron and Steel Institute of Japan (ISIJ).

$$
\mathrm{SiO}_{2}(\mathrm{~s})+3 \mathrm{C}(\mathrm{s})=\mathrm{SiC}(\mathrm{s})+2 \mathrm{CO}(\mathrm{g})
$$

The common refractory of the SEN contains graphite flakes and oxides (such as $\mathrm{Cao}, \mathrm{SiO}_{2}$, and $\mathrm{ZrO}$ ). The main reaction occurs between $\mathrm{SiO}_{2}$ and graphite, and $\mathrm{CO}$ gas is produced. $\mathrm{CO}$ gas flows through the pores of the refractory and reaches the SEN-melt interface (step (2). $\mathrm{CO}$ reacts with $\mathrm{Fe}$ and dissolved $\mathrm{Al}$ and $\mathrm{Ti}$ (step (3) to form a mixture of pure solid alumina and a liquid complex oxide $\left(\mathrm{Fe}_{t} \mathrm{O}-\mathrm{Al}_{2} \mathrm{O}_{3}-\mathrm{TiO}_{x}\right.$, called also "FAT," step (4).

$$
\begin{gathered}
\mathrm{CO} \rightarrow[\mathrm{C}]+[\mathrm{O}] \\
9[\mathrm{O}]+\mathrm{Fe}+[\mathrm{Ti}]+4[\mathrm{Al}] \rightarrow \\
\rightarrow\left(\mathrm{FeO}-\mathrm{Al}_{2} \mathrm{O}_{3}-\mathrm{TiO}_{2}\right) \\
+\mathrm{Al}_{2} \mathrm{O}_{3}
\end{gathered}
$$

The liquid oxide has good wettability and acts as a binder between the SEN and the melt (step (5)). $\mathrm{Fe}_{\mathrm{t}} \mathrm{O}$ in the oxide is reduced by the dissolved $\mathrm{Al}$ and $\mathrm{Ti}$ in the melt or by the graphite from the refractory to form $\mathrm{Fe}$ droplets (step (6)).

$$
\begin{aligned}
& 3\left(\mathrm{FeO}-\mathrm{Al}_{2} \mathrm{O}_{3}-\mathrm{TiO}_{2}\right)+2[\mathrm{Al}] \\
& \quad \rightarrow 3 \mathrm{Fe}+\mathrm{Al}_{2} \mathrm{O}_{3}+3\left(\mathrm{Al}_{2} \mathrm{O}_{3}-\mathrm{TiO}_{2}\right)
\end{aligned}
$$

It is also proposed that other oxides in the refractory $\left(\mathrm{CaO}, \mathrm{SiO}_{2}\right.$, and $\left.\mathrm{ZrO}\right)$ may dissolve in the liquid oxide to form a more complex oxide $\left(\mathrm{CaO}-\mathrm{Al}_{2} \mathrm{O}_{3}-\mathrm{TiO}_{x}-\mathrm{ZrO}_{2}-\right.$ $\mathrm{SiO}_{2}-\mathrm{Fe}_{t} \mathrm{O}$ ). Under these circumstances, the final oxide remaining on the SEN wall would be $\mathrm{CaO}-\mathrm{Al}_{2} \mathrm{O}_{3}-$ $\mathrm{TiO}_{x}-\mathrm{ZrO}_{2}-\mathrm{SiO}_{2}$ together with solid alumina. However, depending on the conditions, some refractory oxides may not dissolve in the liquid oxide. ${ }^{[23]}$

A mathematical formulation based on the scenario proposed by Lee and Kang was proposed and implemented as a sub-model in the transient clogging model.

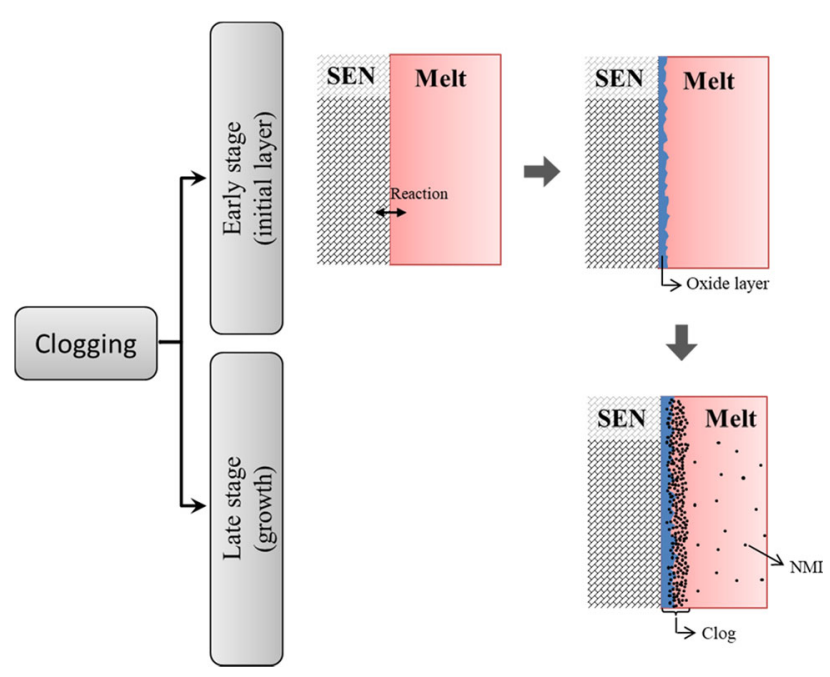

Fig. 2 - Concept of the two-stage clogging model. 


\section{MODEL}

The concept of the two-stage clogging model is illustrated in Figure 2. The clog growth (late stage) model has been described previously. ${ }^{[15]}$ It considers the transport of NMIs by the turbulent melt flow, clog growth due to the deposition of NMIs on the clog front, and the interaction between the clog front and melt flow. Here, only the model extension for early-stage clogging is described.

\section{A. Sub-model of Early-Stage Clogging}

The chemical reaction mechanism proposed by Lee and Kang (Figure 1, Reactions [1] through [4]) is illustrated mathematically in Figure 3 . The entire early stage has been simplified into three steps: (1) formation of $\mathrm{CO}$ gas, (2) $\mathrm{CO}$ gas flow through the oxide layer, and (3) reaction on the oxide-melt interface and consequent thickening of the oxide layer. To quantify the chemical reactions, further thermodynamic and process conditions must be specified. The following considerations and assumptions were made.

- All reactions were isothermal at $1823 \mathrm{~K}$, referring to the practical operation temperature.

- Only the reaction between silica and graphite inside the SEN refractory, Reaction [1], occurred. Possible reactions between the other refractory constituents were ignored.

- Refractory constituents were well mixed, and there was sufficient graphite to react with $\mathrm{SiO}_{2}$ according to reaction [1]. CO gas was homogenously produced inside the refractory. The reaction kinetics were governed by local pressure.

- The SEN refractory was sufficiently permeable to CO gas that it provided no resistance to $\mathrm{CO}$ gas flow. The $\mathrm{CO}$ gas flow was controlled by the oxide layer. The oxide layer was porous, with limited permeability.

- Oxidation Reactions [2] through [3] occurred instantaneously. The oxidation product was $\mathrm{Fe}_{t} \mathrm{O}-\mathrm{Al}_{2} \mathrm{O}_{3}-$ $\mathrm{TiO}_{x}$ with $t=1$ and $x=2$. The reduction of $\mathrm{FeO}$ occurred instantaneously only by dissolved $\mathrm{Al}$ through Reaction [4]. The melt flow in the SEN was highly turbulent, and the oxide layer was always in contact with the fully mixed fresh melt.

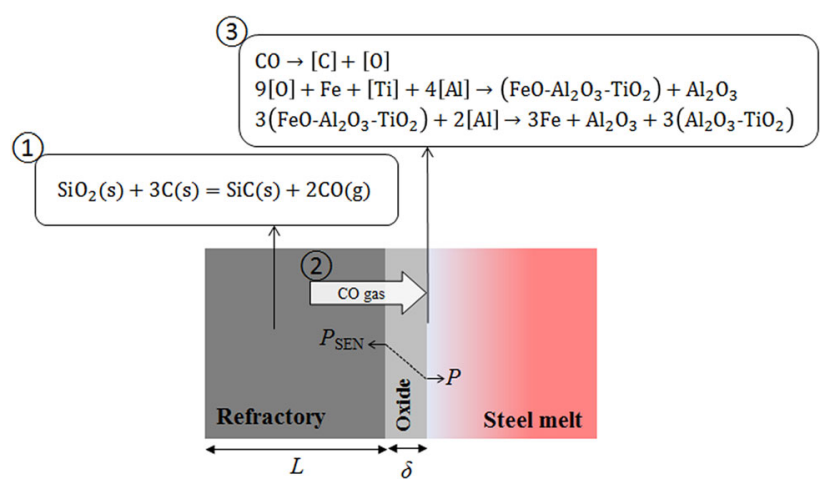

Fig. 3-Mathematical presentation of the chemical reactions and formation of the oxide layer during the early stage of clogging.
- The possible dissolution of SEN refractory constituents in the liquid oxide was neglected; therefore, the final oxidation product was a mixture of $\mathrm{Al}_{2} \mathrm{O}_{3}-\mathrm{TiO}_{x}$ and $\mathrm{Al}_{2} \mathrm{O}_{3}$.

\section{B. Formulations of Early-Stage Clogging}

The reaction kinetics of reaction [1] were determined based on an experiment. ${ }^{[22]}$ Under isothermal (1823 K) and atmospheric pressure $(1 \mathrm{~atm})$ conditions, $2.33 \mathrm{~L}$ $\min ^{-1}\left(0.0156 \mathrm{~mol} \mathrm{~min}^{-1}\right)$ of $\mathrm{CO}$ gas per mole $\mathrm{SiO}_{2}$ was produced. A typical SEN refractory contains $18 \mathrm{wt}$ pct $\mathrm{SiO}_{2}, 40$ wt pet $\mathrm{Al}_{2} \mathrm{O}_{3}, 7$ wt pet $\mathrm{ZrO}_{2}, 8$ wt pet $\mathrm{SiC}$, and 25 wt pct $\mathrm{C}^{[22]}$ For such a refractory, the mass production rate of $\mathrm{CO}$ per volume of refractory $(\dot{m})$ at $1823 \mathrm{~K}$ is $0.048 \mathrm{~kg} \mathrm{~s}^{-1} \mathrm{~m}^{-3}$. Based on the experimentally determined $\dot{m}$ and stoichiometric coefficients (reactions [2] through [4]), the volume production rates of different oxide products per volume of refractory $\left(\mathrm{s}^{-1}\right)$ are calculated as follows:

$$
\begin{gathered}
\dot{V}_{\mathrm{F}}=\frac{\dot{m}}{9 M_{\mathrm{CO}}} \frac{M_{\mathrm{F}}}{\rho_{\mathrm{F}}}, \\
\dot{V}_{\mathrm{A}}=\frac{\dot{m}}{M_{\mathrm{CO}}}\left(\frac{1}{9}+\frac{1}{9 \times 3}\right) \frac{M_{\mathrm{A}}}{\rho_{\mathrm{A}}}, \\
\dot{V}_{\mathrm{AT}}=\frac{\dot{m}}{9 M_{\mathrm{CO}}} \frac{M_{\mathrm{AT}}}{\rho_{\mathrm{AT}}} .
\end{gathered}
$$

$M$ and $\rho$ denote the molar mass $\left(\mathrm{g} \mathrm{mol}^{-1}\right)$ and density $\left(\mathrm{kg} \mathrm{m}^{-3}\right)$, and the subscripts $\mathrm{F}, \mathrm{A}$, and AT represent Fe, $\mathrm{Al}_{2} \mathrm{O}_{3}$, and $\mathrm{Al}_{2} \mathrm{O}_{3}-\mathrm{TiO}_{2}$, respectively. It should be mentioned that FAT does not have a fixed stoichiometry, as shown by the unknown indices $\mathrm{x}$ and $\mathrm{t}$. This is due to the transition metals ( $\mathrm{Fe}$ and $\mathrm{Ti}$ ) and wide range of compositions in this oxide. Therefore, the stoichiometric numbers that appear in Equations [5] through [7] can change depending on the formation conditions of the FAT, which subsequently affects the calculation results. It is difficult to define $x$ and $t$ in $\mathrm{Fe}_{t} \mathrm{O}-\mathrm{Al}_{2} \mathrm{O}_{3}-$ $\mathrm{TiO}_{x}$; therefore, in this study, $\mathrm{FeO}-\mathrm{Al}_{2} \mathrm{O}_{3}-\mathrm{TiO}_{2}$ was selected as an approximation to develop the model.

According to Equations [5] through [7], the growth rate of the oxide layer, i.e., the rate of increase of its thickness $\left(\mathrm{m} \mathrm{s}^{-1}\right)$, can be calculated as follows:

$$
\dot{\delta}=\left(\dot{V}_{\mathrm{F}}+\dot{V}_{\mathrm{A}}+\dot{V}_{\mathrm{AT}}\right) \times L,
$$

where $L$ is the thickness of the SEN refractory that participates in chemical reaction [1]. It is known that the wettability of the final oxide network by liquid iron is very low. ${ }^{[21]}$ Therefore, the reduced iron is assumed to be expelled from the oxide network, and it is replaced by $\mathrm{CO}$ gas coming from the refractory side. $\mathrm{CO}$ gas at the refractory-oxide interface can penetrate through the pores of the oxide layer, reach the melt, and react with the melt, as illustrated in Figure 3. The permeability of the oxide layer $\left(k_{\text {per }}\right)$ plays an 
important role in controlling the transport of $\mathrm{CO}$ gas through the thickness of the oxide layer $(\delta)$. Darcy's law was applied to calculate the pressure drop in the oxide layer.

$$
P_{\mathrm{SEN}}-P=\frac{\dot{m} L \mu \delta}{\rho k_{\mathrm{per}}},
$$

$\mu$ and $\rho$ are the viscosity and density of $\mathrm{CO}$ gas, respectively; $P_{\mathrm{SEN}}$ and $P$ are the pressures on both sides of the oxide layer.

In carbothermic reaction [1], $\mathrm{CO}$ is the only gaseous component. The standard Gibbs energy change of this reaction is $-11206 \mathrm{~J} \mathrm{~mol}^{-1}$ at $1823 \mathrm{~K}$, which was calculated using FactSage software. ${ }^{[2]}$ If there are no other gaseous components in the system, the equilibrium partial pressure of $\mathrm{CO}\left(P_{\mathrm{CO}, \mathrm{eq}}\right)$ is $1.447 \mathrm{~atm}$. As long as $P_{\mathrm{CO}}<P_{\mathrm{CO} \text {,eq }}$, the Gibbs energy change is negative, and $\mathrm{CO}$ gas is produced spontaneously. This condition $\left(P_{\mathrm{CO}}<P_{\mathrm{CO}, \text { eq }}\right)$ is mostly fulfilled during continuous casting. The pressure on the refractory surface $\left(P_{\mathrm{SEN}}\right)$ increases when the porous medium of the oxide layer forms. $P_{\mathrm{SEN}}$ can be considered as the pressure of the thermodynamic system of reaction [1], i.e., $P_{\mathrm{SEN}} \equiv P_{\mathrm{CO}}$, which increases with the thickness of the oxide layer $(\delta)$. When $\delta$ is sufficiently thick, $P_{\mathrm{SEN}}$ reaches $P_{\mathrm{CO}, \text { eq }}$, and Reaction [1] terminates. In other words, the $\mathrm{CO}$ gas production rate $\left(\dot{m}_{0}\right)$ decreases from its maximum value $\left(0.048 \mathrm{~kg} \mathrm{~s} \mathrm{~m}^{-3}\right)$ at atmospheric pressure $\left(P_{\mathrm{SEN}}=P_{\mathrm{atm}}\right)$ to zero at $P_{\mathrm{SEN}}=P_{\mathrm{CO}, \text { eq }}$. For simplicity, a linear function was assumed.

$$
\dot{m}=\frac{\dot{m}_{0}}{P_{\mathrm{atm}}-P_{\mathrm{CO}, \mathrm{eq}}}\left(P_{\mathrm{SEN}}-P_{\mathrm{CO}, \mathrm{eq}}\right)
$$

By combining Equations [9] and [10], the CO gas production rate $(\dot{m})$ can be expressed as a function of the pressure on the oxide-melt interface $(P)$.

$$
\dot{m}=\frac{\dot{m}_{0} \rho k_{\mathrm{per}}\left(P_{\mathrm{CO}, \mathrm{eq}}-P\right)}{\dot{m}_{0} L \mu \delta+\rho k_{\mathrm{per}}\left(P_{\mathrm{CO}, \mathrm{eq}}-P_{\mathrm{atm}}\right)}
$$

Based on Equations [5] through [8] and [11], the growth rate of the oxide layer $(\dot{\delta})$ was calculated as a function of $P$, which can be obtained from a computational fluid dynamics (CFD) simulation of the melt flow in the SEN.

\section{Configurations of Simulation Cases}

To evaluate the sub-model for early-stage clogging, a one-dimensional (1D) case was simulated to track the formation of the initial oxide layer $(\delta)$. The chemical reaction between the SEN refractory and melt was the only mechanism, i.e., no NMI deposition from the steel melt was considered. The configuration of the 1D geometry is shown in Figure 3. The physical properties at $1823 \mathrm{~K}$ and the calculation parameters are listed in Table I. The thickness of the refractory $(L)$ was chosen according to the typical SEN used for Ti-ULC steel. It was assumed that all the $\mathrm{CO}$ gas produced in the SEN refractory went to the inner side of the SEN and reacted with the melt. The pressure of the steel melt $(P)$ varies with the melt velocity, argon injection, and filling conditions. $^{[24,25]}$ Therefore, according to the reported values of pressure inside the SEN, ${ }^{[24,25]}$ a range of $\mathrm{P}(0.2$ to $1.4 \mathrm{~atm}$ ) was considered. Because the permeability of the oxide layer $\left(k_{\text {per }}\right)$ is unknown, a parameter study was performed by varying it in the range $10^{-18}-10^{-15} \mathrm{~m}^{2}$ based on reported gas permeability values in tight porous medium. ${ }^{[26]}$

A combined clogging model considering both the early and late stages was used for the simulation of an industrial-scale case, as shown in Figure 4. The calculations were performed in 3D. Owing to the high calculation cost, only a small section of the SEN was considered: a $5^{\circ}$ sector with a length $l=38 \mathrm{~mm}$. A fully developed flow profile with a mass flow rate of $0.389 \mathrm{~kg}$ $\mathrm{s}^{-1}$ was applied to the inlet surface. A pressure outlet boundary condition was assigned to the bottom boundary. The absolute pressure was set to 1 atm at the center point of the outlet. A nonslip boundary was applied to the SEN wall. Two vertical boundaries were set as symmetry surfaces. Since the size of alumina inclusions, which are mostly responsible for later stage of clogging, is typically in the range of 1 to $10 \mu \mathrm{m},{ }^{[9,27]}$ alumina spherical particles with average diameter of $6 \mu \mathrm{m}$ were assumed and uniformly injected at the inlet. The injection rate of the NMIs was ten million per second. To evaluate the NMI injection rate, a rough estimation was done. On one hand, for a melt flow rate of $0.389 \mathrm{~kg}$ $\mathrm{s}^{-1}$, the volume fraction of NMIs was $2.27 \times 10^{-5}$. On the other hand, if the oxygen concentration in the bulk of the melt is $5 \mathrm{ppm}$ and all the oxygen reacts with dissolved aluminum, the volume fraction of alumina inclusions can be estimated to be $2.24 \times 10^{-5}$. Hence, the selected NMI injection rate looks comparable to that under real operation conditions. The density and viscosity of the steel melt were set to $7800 \mathrm{~kg} \mathrm{~m}^{-3}$ and 0.006 $\mathrm{kg} \mathrm{m} \mathrm{m}^{-1}$, respectively. The density of alumina particles was $3700 \mathrm{~kg} \mathrm{~m}^{-3}$. A hexahedral mesh was generated for the computational domain; the minimum cell size was $8.01 \times 10^{-12} \mathrm{~m}^{3}$ located near the nozzle wall; the maximum cell size was $3.22 \times 10^{-10} \mathrm{~m}^{3}$ located in the center region.

The reaction between the $\mathrm{CO}$ gas and the steel melt initiates clogging. The fresh SEN wall is completely inert to the suspended NMIs, i.e., NMIs rebound as they hit the fresh SEN wall. After an oxide layer forms on the SEN surface, NMIs can be deposited on the oxide layer. Here, a critical thickness of the oxide layer $\left(\delta_{\mathrm{cr}}\right)$ is defined for NMI deposition to begin. Based on metallographic analysis of the as-clogged SEM sample, a $\delta_{\mathrm{cr}}$ of $1 \mu \mathrm{m}$ was found to be sufficient to initiate NMI deposition. After the formation of the critical thickness $\delta_{\mathrm{cr}}$ of the oxide layer, both clogging mechanisms, i.e., chemical reaction and NMI deposition, operate simultaneously to form the porous network of the clog, and the two mechanisms compete with each other. An average permeability for the clog was considered, $10^{-17}$ $\mathrm{m}^{2}$. When the clog reaches a certain thickness, the chemical reaction terminates, but NMI deposition continues and acts as the only mechanism for clog growth. 
Table I. Physical Properties (at 1823 K) and Calculation Settings for the Sub-model of Early-Stage Clogging

\begin{tabular}{lcll}
\hline Molar Mass, $M_{x x}\left(\mathrm{~g} \mathrm{~mol}^{-1}\right)$ & & density, $\rho_{x x}\left(\mathrm{~kg} \mathrm{~m}^{-3}\right)$ & \\
$\mathrm{Fe}$ & 55.84 & $\mathrm{Fe}$ & 7800 \\
$\mathrm{Al}_{2} \mathrm{O}_{3}$ & 101.96 & $\mathrm{Al}_{2} \mathrm{O}_{3}$ & 3700 \\
$\mathrm{Al}_{2} \mathrm{O}_{3}-\mathrm{TiO}_{2}$ & 181.83 & $\mathrm{Al}_{2} \mathrm{O}_{3}-\mathrm{TiO}_{2}$ & 3950 \\
$\mathrm{CO}$ & 28.01 & $\mathrm{CO}$ & 0.188 \\
$\mathrm{Viscosity}, \mu(\mathrm{Pa} \mathrm{s})$ & $5.7 \times 10^{-5}$ & permeability, $k_{\text {per }}\left(\mathrm{m}^{2}\right)$ & \\
$\mathrm{CO}$ & 0.02 & oxide network & $10^{-18}-10^{-15}$ \\
Refractory thickness, $L(\mathrm{~m})$ & pressure, $P(\mathrm{~atm})$ & $0.2-1.4$ \\
\hline
\end{tabular}
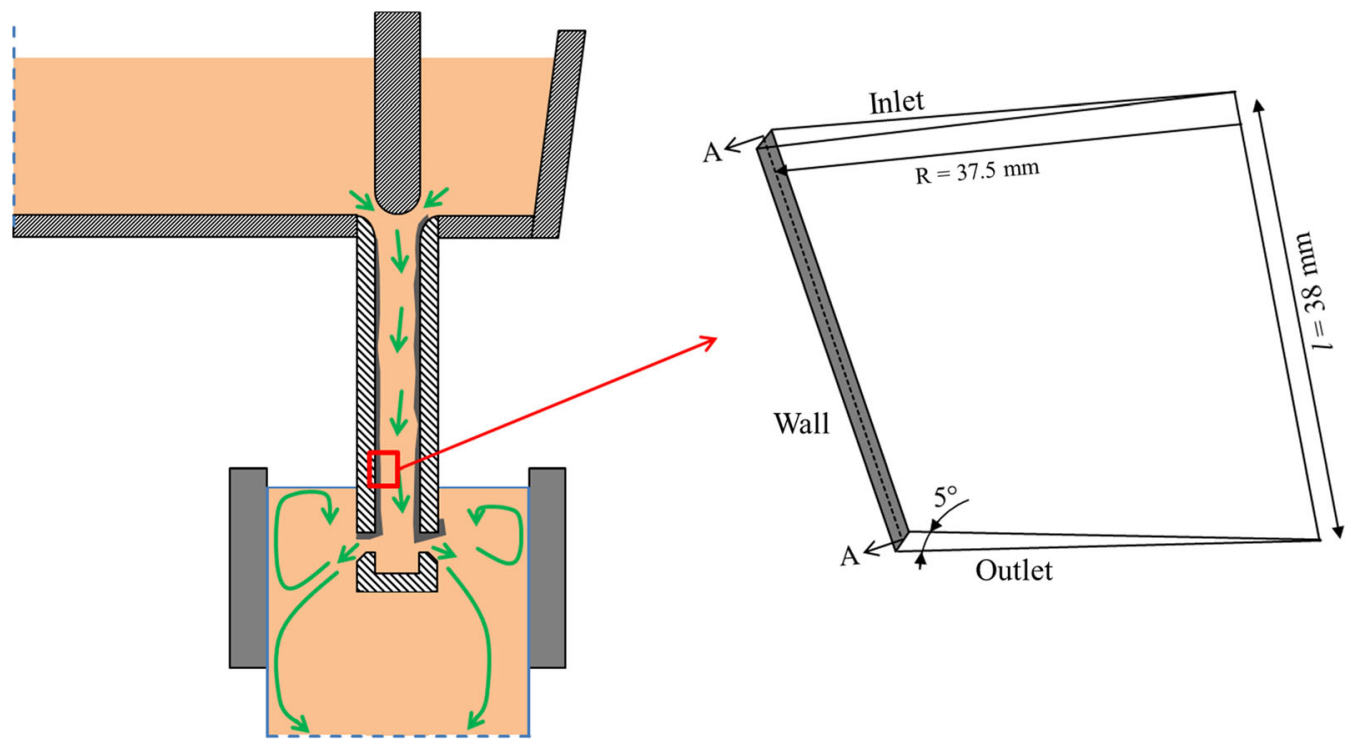

Fig. 4-Configuration of the computational domain taken from an industrial-scale case.

\section{RESULTS}

\section{A. Sub-model for Early-Stage Clogging}

The sub-model was used to simulate the 1D case shown in Figure 3. The modeling results are shown in Figure 5: $P_{\mathrm{SEN}}$ and $\dot{m}$ as functions of $\delta$. The equilibrium $\mathrm{CO}$ pressure $\left(P_{\mathrm{CO}, \text { eq }}\right)$ for the given temperature of 1823 $\mathrm{K}$ is also plotted (dotted line). With the growth of the oxide layer, i.e., increasing $\delta, P_{\mathrm{SEN}}$ increased from the initial $1 \mathrm{~atm}$ to a value very close to $P_{\mathrm{CO} \text { eq, }}$, while $\dot{m}$ decreased from its initial value of $0.048 \mathrm{~kg} \mathrm{~s}^{-1} \mathrm{~m}^{-3}$ to zero. Mathematically, $\dot{m}=0$ or $P_{\text {ref }}=P_{\text {CO.eq }}$ when $\delta \rightarrow \infty$. Here, a physical threshold was defined to determine the termination of the growth of $\delta$ : $P_{\mathrm{SEN}}=0.99 P_{\mathrm{CO}, \text { eq }}$. In this case, when $P_{\mathrm{SEN}}$ reached $0.99 P_{\mathrm{CO} . \text { eq }}$, the growth of $\delta$ terminated at $\delta=46.6 \mu \mathrm{m}$ and $\dot{m}=1.55 \times 10^{-3} \mathrm{~kg} \mathrm{~s}^{-1} \mathrm{~m}^{-3}$. Note that the late stage of clogging, i.e., the deposition of NMIs, was not considered in this case.

The modeling results of $P_{\mathrm{SEN}}, \dot{m}, \delta$, and $\dot{\delta}$ as functions of time are shown in Figure 6. Rapid changes in $P_{\mathrm{SEN}}$, $\dot{m}$, and $\dot{\delta}$ occurred in the first 600 seconds. At 2168 seconds, $P_{\text {ref }}=0.99 P_{\mathrm{CO}, \mathrm{eq}}$, and the oxide layer growth terminated at $\delta=46.6 \mu \mathrm{m}$. Lee and $\mathrm{Kang}^{[21]}$ conducted laboratory-scale experiments using a rotating finger

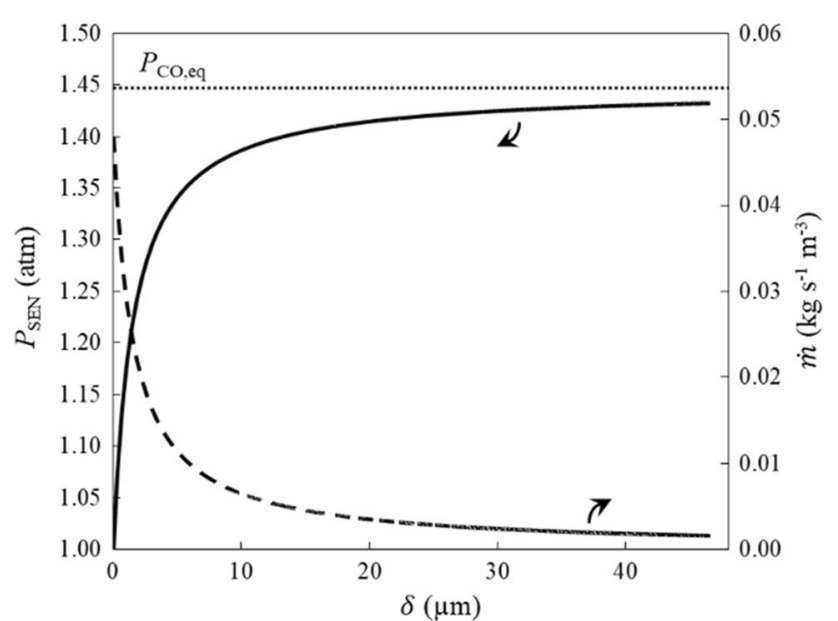

Fig. 5-Modeling result for early-stage clogging: $P_{\mathrm{SEN}}$ and $\dot{m}$ as functions of $\delta . k_{\text {per }}=1 \times 10^{-17} \mathrm{~m}^{2}, P=1 \mathrm{~atm}$, and $L=0.02 \mathrm{~m}$.

method for different types of SEN refractories in Ti-ULC steel. After 30 minutes (1800 seconds), the thickness of the oxide layer reached 50 to $90 \mu \mathrm{m}$. If the reported conditions in the rotating finger are used in the current mathematical model, the thickness of the oxide 
layer would be $\sim 51 \mu \mathrm{m}$, which is comparable with the reported values in the experiments. It is worth mentioning that the permeability of the oxide layer is an important uncertain parameter in the present early-stage model. Further discussion is provided in a later section.

\section{B. Combined Model for Both the Early and Late Stages of Clogging}

The combined model was used to simulate an industrial-scale case in 3D (Figure 4). The simulation results are shown in Figure 7 . The total clog thickness $\left(\delta_{\text {clog }}\right)$, considering both the early and late stages of clogging, was evaluated. $\delta_{\text {clog }}$ in the lower area was greater than that in the upper area. This was due to the special configuration of the boundary and the initial conditions of the test case. The NMIs, homogenously injected from the inlet, required time to respond to turbulent flow. Because the residence time of NMIs in the turbulent flow was longer in the lower area, they had a longer time to respond to the turbulence; hence, they had a greater chance of reaching the SEN wall in the lower area. After 85 seconds, the growth of $\delta_{\text {clog }}$ by chemical reaction (early stage) terminated, and NMI deposition became the only mechanism for its further growth. After 300 seconds, the maximum clog thickness $(62.5 \mu \mathrm{m})$ was still very small compared to the computational cell size $(\sim 500 \mu \mathrm{m})$. Therefore, the late stage of clogging is still well treated by enhancing the SEN wall roughness. ${ }^{[15]}$ With further clog growth, the deposition pattern changed at 1920 seconds, as shown on the right-hand side of Figure 7 . Clog growth has a self-acceleration nature, and some areas of the clog front start to develop a bulged profile. Clog growth leads to a more turbulent flow; more turbulent flow results in more NMI deposition and faster growth of the clog.

In Figure 8(a), profiles of the oxide layer thickness (early stage) and deposit thickness (late stage) on the wall centerline (line AA in Figure 4) are plotted at equal time intervals of 20 seconds. Thus, the sum of the two

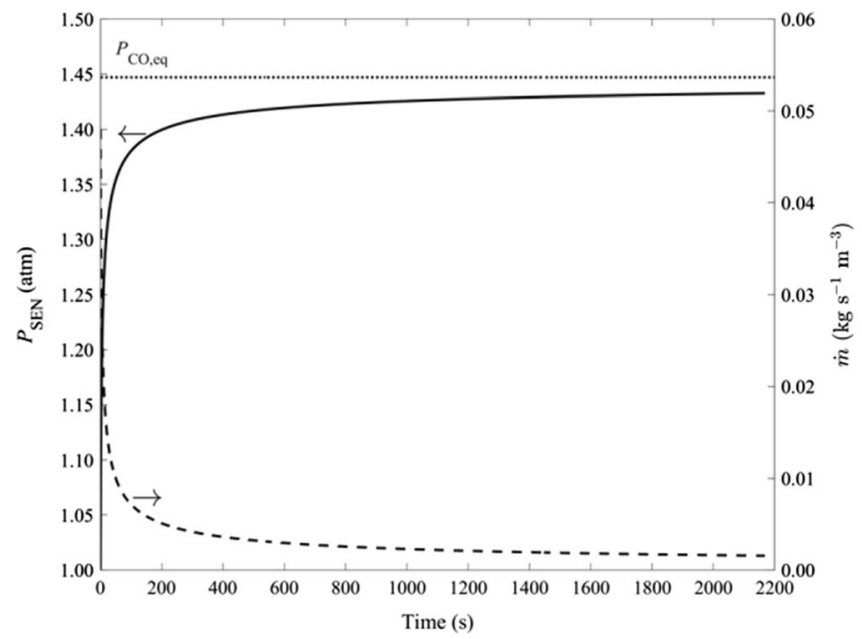

(a) profiles gives the total thickness of the clog $\delta_{\text {clog }}$. Because oxide layer growth terminated after 85 seconds, profiles of the early stage after this time overlap one another, and only one curve is visible. Initially, the profile of the early stage was almost flat because the pressure field $\left(P_{\mathrm{SEN}}\right)$ and clog thickness $\left(\delta_{\text {clog }}\right)$ were almost uniform along the SEN wall. The random deposition of NMIs resulted in a non-uniform $\delta_{\text {clog }}$. Therefore, after a period of time (e.g., 100 seconds), the early-stage profile became non-uniform. In the lower area, the clog was thicker; hence, the early-stage thickness decreased with increasing distance from the inlet. The late-stage profiles became wavy, and the amplitude of the fluctuations increased as clogging progressed. This was due to the fact that bulges on a rough wall are more favorable locations for NMI deposition.

The growth rate for each stage is shown in Figure 8(b). The growth of the early stage began with the maximum growth rate and gradually reduced to zero. After 85 seconds, the growth rate of the early stage terminated along the entire SEN wall. The growth rate of the late stage oscillated with time. The time-averaged profile is also plotted (solid line). The oscillation remained within a certain range because the effect of clog growth on turbulence in this short time (300 seconds) was negligible. When $\delta_{\text {clog }}$ was sufficiently thick than it could influence the melt flow, the clog growth rate increased. For example, in Figure 7, the maximum clog growth rate is $15.7 \mu \mathrm{m} \mathrm{s}^{-1}$ at 1920 seconds, which is approximately 100 times larger than that at 20 to 300 seconds.

The fraction (contribution) of early-stage clog growth in the total clog thickness as a function of the distance from the inlet is shown in Figure 9. On the top $10 \mathrm{~mm}$ of the SEN wall, a very small quantity of NMIs deposited; therefore, the clog consisted almost entirely of the oxide layer. Below this area, the volume fraction of the oxide layer decreased. After 20 seconds, the contributions of

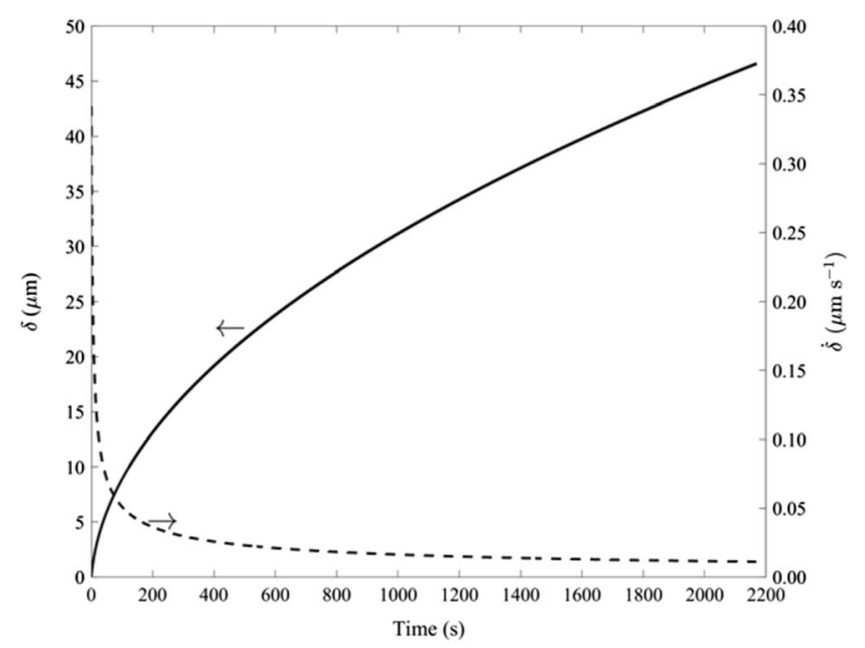

(b)

Fig. 6-Modeling results for early-stage clogging as functions of time: (a) $P_{\mathrm{SEN}}$ and $\dot{m},(b) \delta$ and $\dot{\delta} . k_{p e r}=1 \times 10^{-17} \mathrm{~m}^{2}, P=1 \mathrm{~atm}$, and $L=$ $0.02 \mathrm{~m}$. 
Total thickness of $\operatorname{clog}(\mu \mathrm{m})$
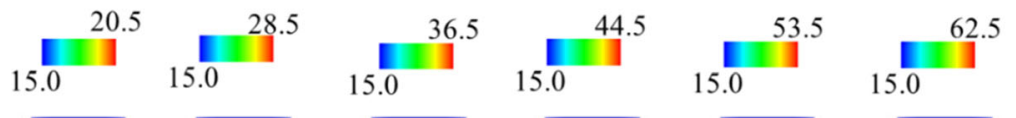

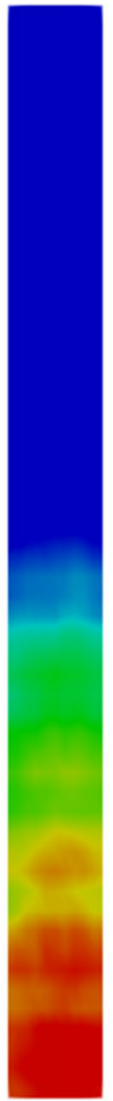

$50 \mathrm{~s}$

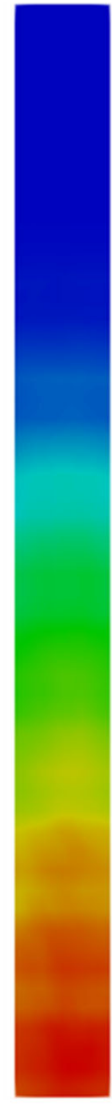

$100 \mathrm{~s}$

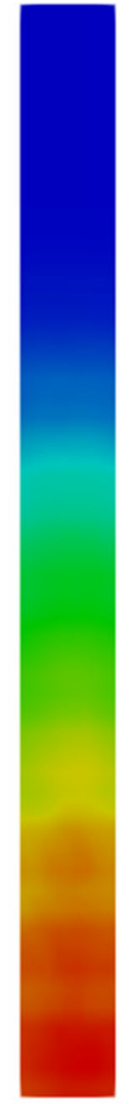

$150 \mathrm{~s}$

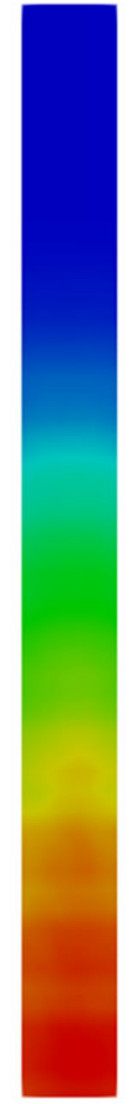

$200 \mathrm{~s}$

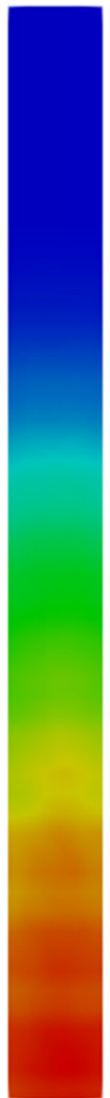

$250 \mathrm{~s}$

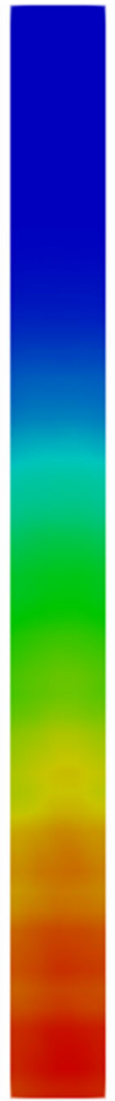

$300 \mathrm{~s}$

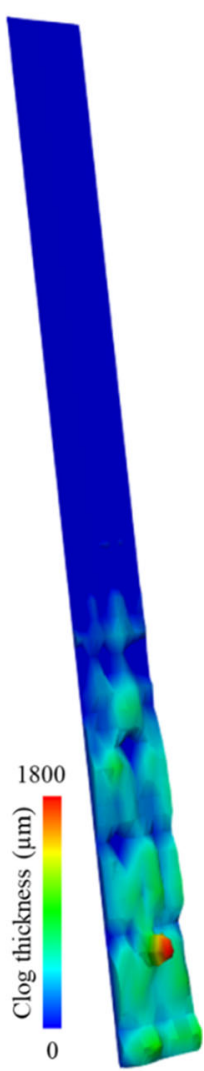

$1920 \mathrm{~s}$

Fig. 7-Evolution of the total clog thickness $\left(\delta_{\text {clog }}\right)$ considering both the early and late stages of clogging.

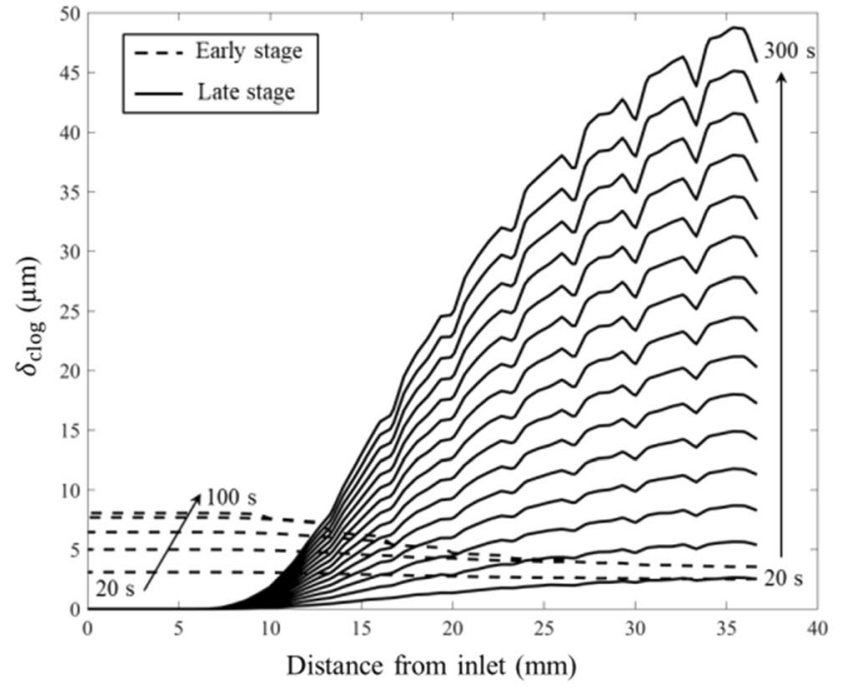

(a)

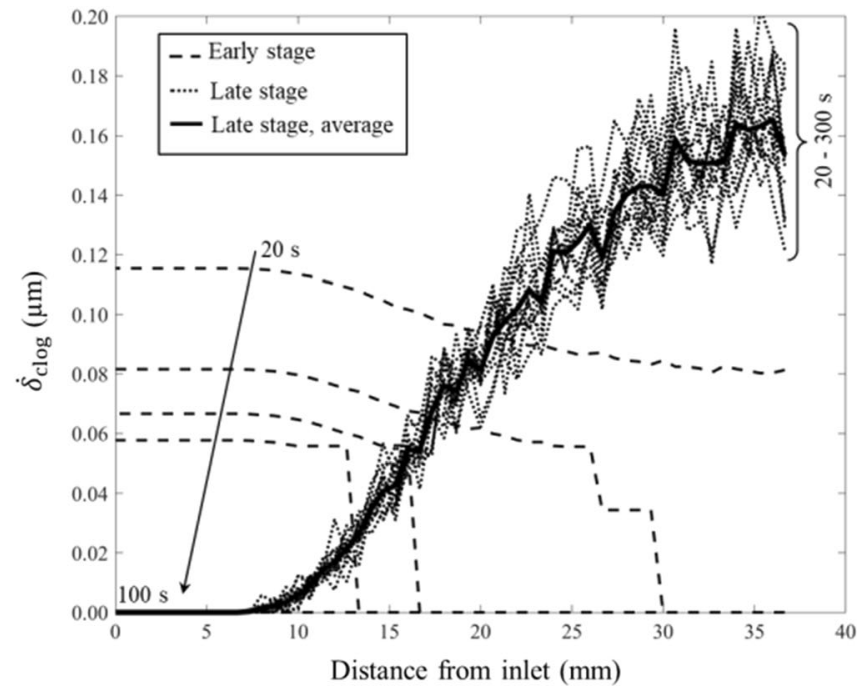

(b)

Fig. 8- (a) Thickness, $\delta$, and $(b)$ growth rate, $\dot{\delta}$, of the two stages of clogging on the centerline of the wall. The time interval between the curves is $20 \mathrm{~s}$. 
the two stages were almost equal in the bottom part of the domain. After that, NMI deposition dominated most of the clog.

By comparing the simulation results of the combined model (Figure 8) with those of the pure early-stage model (Figure 6), it can be concluded that the deposition of suspended NMIs causes the oxide layer growth to terminate earlier. In the combined model, the oxide layer growth terminated at 85 seconds, while in the pure early-stage case, it occurred at 2168 seconds. This illustrates the effect of the late stage on the early stage: late-stage growth leads to earlier termination of earlystage growth. The effect of early-stage growth on late-stage growth is explained by "activation" of the SEN surface for NMI deposition. This effect in the current results is negligible because a small piece of the SEN was simulated, and the pressure, as the main influencing parameter in the early-stage model, was almost constant. The pressure field changes significantly along the entire SEN; therefore, a variable growth rate during the early stage is expected. This point is explained in Section IV-C.

In the current combined model, early-stage growth is a function of the refractory chemistry and pressure field in the melt flow; late-stage growth depends on the velocity, turbulence, size, and number density of NMIs. The model correlates several important parameters for the clogging tendency in the continuous casting of Ti-ULC. Therefore, it has great potential to be further developed to optimize the continuous casting of Ti-ULC steel to avoid clogging.

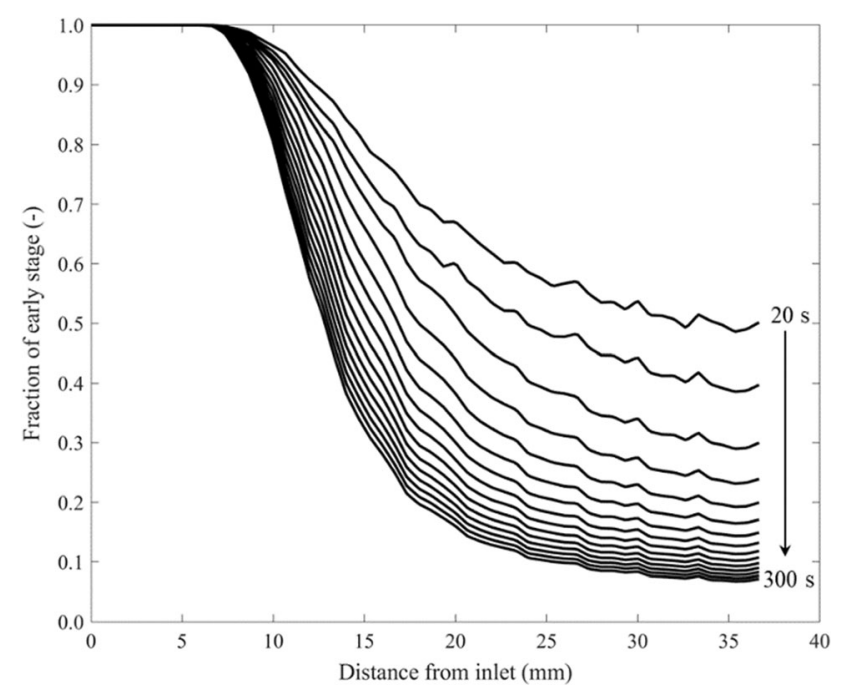

Fig. 9-Fraction (contribution) of early-stage clog growth in the total clog thickness, $\delta_{\text {clog, }}$, on the centerline of the SEN wall. The curves are plotted at equal time intervals of $20 \mathrm{~s}$.

\section{PARAMETER STUDY AND DISCUSSION}

\section{A. Validation of the Model}

The higher sensitivity of Ti-ULC steel to clogging has been explained via oxide stability diagrams obtained by computational thermodynamics. ${ }^{[20,21]}$ An example diagram of the $\mathrm{Fe}-\mathrm{Al}-\mathrm{Ti}-\mathrm{O}$ system representing Ti-ULC steel is shown in Figure 10(a). The concentration of oxygen in ppm is also shown with isolines. The bulk of Ti-ULC steel, where the oxygen content is very low and alumina is the stable oxide, is marked as "Region A" in Figure 10(a). At the SEN-melt interface, the oxygen content increases locally owing to the dissolution of $\mathrm{CO}$ gas in the melt. In this case, liquid oxide $\left(\mathrm{Fe}_{t} \mathrm{O}-\mathrm{Al}_{2} \mathrm{O}_{3}-\right.$ $\mathrm{TiO}_{x}$ ) is the stable oxide, marked as "Region B." The liquid oxide has high wettability with both the SEN refractory and steel melt; hence, it can spread easily on the SEN wall. The formation of the liquid oxide phase is thought to be an important cause of the more severe clogging tendency of Ti-ULC steel in comparison with that of Ti-free ULC steel. ${ }^{[10,21]}$ An example of the oxide layer that formed on the SEN refractory during a rotating finger experiment is shown in Figure 10(b) ${ }^{[2 \mathrm{~T}]} \mathrm{It}$ shows two distinct oxide layers: $\mathrm{Al}_{2} \mathrm{O}_{3}-\mathrm{TiO}_{x}$ on the refractory side and pure $\mathrm{Al}_{2} \mathrm{O}_{3}$ on the steel melt side. Generally, two types of alumina can be found in the clog deposit: one from the chemical reaction between the SEN and the steel melt (through the formation of $\mathrm{Fe} /$ $\mathrm{Al}_{2} \mathrm{O}_{3} / \mathrm{Al}_{2} \mathrm{O}_{3}-\mathrm{TiO}_{x}$ from FAT) and the other from the deposition of the suspended NMIs in the steel melt. Although NMIs were suspended in the melt in the rotating finger experiment, they rarely reached the rotating refractory. Because the rotation of a refractory cylinder with a diameter of $10 \mathrm{~mm}$ and a speed of 100 rpm in the steel melt leads to an almost laminar flow, suspended NMIs cannot reach the refractory surface. Therefore, the oxide layer in Figure 10(b) is the result of the refractory-melt reaction.

According to Figure 10(b), liquid $\mathrm{Fe}_{t} \mathrm{O}-\mathrm{Al}_{2} \mathrm{O}_{3}-\mathrm{TiO}_{x}$ forms first; $\mathrm{Fe}_{t} \mathrm{O}$ is reduced by dissolved $\mathrm{Al}$; the liquid $\mathrm{Fe}$ is driven out of the pores of the oxide network; and finally, $\mathrm{Al}_{2} \mathrm{O}_{3}-\mathrm{TiO}_{x}$ remains as the final product. After a period of time, $\mathrm{Fe}_{t} \mathrm{O}-\mathrm{Al}_{2} \mathrm{O}_{3}-\mathrm{TiO}_{x}$ does not form anymore, and pure $\mathrm{Al}_{2} \mathrm{O}_{3}$ forms instead. In other words, $\mathrm{Al}_{2} \mathrm{O}_{3}$ is the stable oxide instead of $\mathrm{Fe}_{t} \mathrm{O}-\mathrm{Al}_{2} \mathrm{O}_{3}-\mathrm{TiO}_{x}$, i.e., there is a transformation from "Region $\mathrm{B}$ " to "Region A" in Figure 10(a). This transformation occurs when the oxygen content is reduced at the oxide-melt interface during the process. Therefore, based on this explanation, Figure 10 provides evidence that supports the considered scenario in the early stage of clogging that the termination of $\mathrm{CO}$ gas production is due to the growth of the porous oxide layer.

In this study, the $\mathrm{CO}$ gas production rate was extracted from an experiment using a mixture of fine silica and graphite powder ( 35 and $\sim 2 \mu \mathrm{m}$, respectively), representing the refractory composition, under specific conditions of $1 \mathrm{~atm}$ and $1823 \mathrm{~K}$ [22]. Unlike the experimental sample, real refractory constituents are neither fine nor well-mixed. Therefore, the measured $\mathrm{CO}$ production rate can be assumed to be an extreme case 


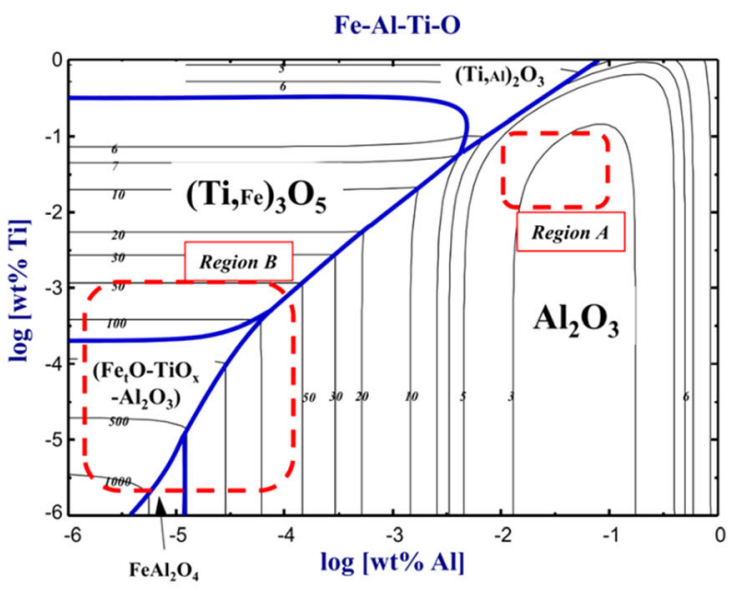

(a)

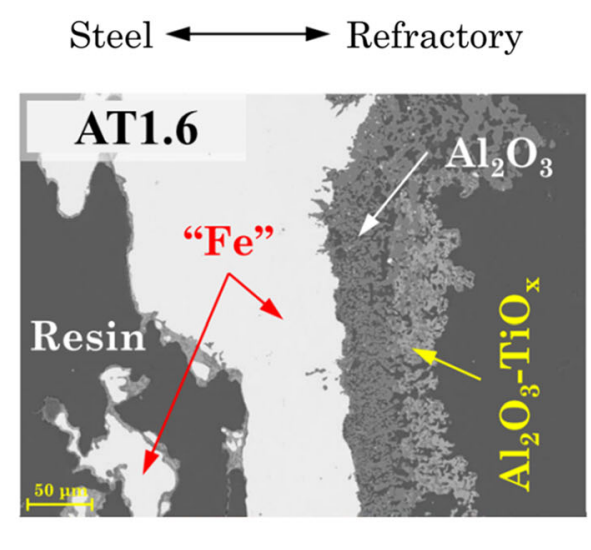

(b)

Fig. 10-(a) Oxide stability diagram of the $\mathrm{Fe}-\mathrm{Al}-\mathrm{Ti}-\mathrm{O}$ system at $1540{ }^{\circ} \mathrm{C}$ and $1 \mathrm{~atm}^{[20]}$; isoline labels represent the oxygen concentration in ppm. (b) Metallographic image of a deposit found on a nozzle refractory that reacted with Ti-ULC steel in a rotating finger experiment. ${ }^{[21]}$ Both parts are reprinted with permission from Iron and Steel Institute of Japan (ISIJ).

for oxide formation and clogging. Information on the $\mathrm{CO}$ production rate is available only for the typical operating temperature $(1823 \mathrm{~K})$. Because the melt flow inside the SEN is quite fast, and the outer surface of the SEN typically has an isolating cover, the temperature change in the melt during the early stage of clogging could be negligible. Hence, information on the kinetics of $\mathrm{CO}$ production at the operating temperature is sufficient.

It was assumed that the permeability of the SEN refractory to $\mathrm{CO}$ gas was sufficiently high that $\mathrm{CO}$ gas flowing through refractory pores did not cause any pressure drop. Laboratory ${ }^{[28]}$ and plant ${ }^{[4]}$ scale investigations on the permeability of SEN refractories have shown that SEN permeability does not play a significant role in clogging. Therefore, the above assumption of a large permeability of the SEN refractory appears reasonable.

The assumption that the liquid iron reduced from $\mathrm{Fe}_{\mathrm{t}} \mathrm{O}$ can be driven out of the oxide network toward the steel melt can be attributed to the following two major reasons: low wettability of the oxide solid network by liquid $\mathrm{Fe}$ and the pressure of $\mathrm{CO}$ gas coming from the refractory side. Figure 10(b) supports this scenario because Fe drops can hardly be observed in the oxide network. However, Fe drops were observed in more complex cases where refractory constituents, such as $\mathrm{CaO}$, can dissolve in the liquid oxide. ${ }^{[23]}$

It was assumed that the oxide layer was a homogenous porous medium, and certain values of porosity and permeability could be defined for it. In reality, different types of oxides with different porosities, permeabilities, and chemistries may form on the SEN surface, as shown in Figure 10(b). Therefore, the average and effective values should be considered for porosity and permeability.

\section{B. Effect of the Porosity and Permeability of the Oxide Layer on Clogging}

An important consideration of this work is that the $\mathrm{CO}$ gas flow through the oxide layer controls the early-stage growth rate. The permeability of the oxide layer is an unknown parameter. Normally, there is a correlation between the permeability and porosity of a porous medium. According to the previous assumption that liquid $\mathrm{Fe}$ is driven out of the oxide network, the porosity should be equal to the volume fraction of $\mathrm{Fe}$ in the final product of the reactions. Considering Equations [5] through [7], the porosity of the oxide network is $\sim 8$ pct in the ideal case. Although metallographic images, as shown in Figure 10(b), provide some insight into the structure of the oxide network, it remains difficult to quantitatively determine the porosity from metallography. Moreover, in 2D metallography, part of the oxide network on the surface can be broken during cutting and sample preparation. Because information about the structure of the oxide network is very limited, using empirical equations, such as Carman-Kozeny, does not help to determine the permeability from the porosity. In this study, a range of permeabilities $\left(10^{-18}-10^{-15} \mathrm{~m}^{2}\right)$ was considered based on the values reported for gas permeability in tight porous media. ${ }^{[26]}$

In Figure 11, pure early-stage growth of the oxide layer over time is depicted for various values of permeability in the early-stage model. For better visualization, the quantities are presented on a logarithmic scale. The $\delta$ curves terminate when $P_{\text {ref }}=0.99 P_{\mathrm{CO} \text {,eq }}$. This shows that with increasing permeability, the growth rate of the oxide layer increased. Very large values of permeability, $\log \left(k_{\text {per }}\right)>-16$, led to the termination of growth after a very long time, longer than $2 \times 10^{5}$ seconds. In practice, the SEN is replaced with a new one after a few hours of operation, even without severe clogging, for safety reasons. Therefore, if the permeability of the oxide layer is high, the early stage of clogging can last for a very long time. Moreover, there is a limitation for the thickness of the oxide layer. The 
oxide layer grows until the $\mathrm{SiO}_{2}$ content in the $\mathrm{SEN}$ is completely consumed. If the $\mathrm{CO}$ production rate remains constant, based on the parameters in this study, consumption of all the $\mathrm{SiO}_{2}$ will result in an oxide layer that is $2600 \mu \mathrm{m}$ thick. It is known that the reaction rate is reduced as the reactants are consumed. Hence, 2600 $\mu \mathrm{m}$ is an exaggerated thickness of the oxide layer.

\section{Effect of Pressure on Clogging}

One of the major advantages of the current sub-model for the early stage of clogging is that it correlates the pressure field of the melt flow, as a fluid dynamic parameter, to the melt-refractory reaction and clogging.

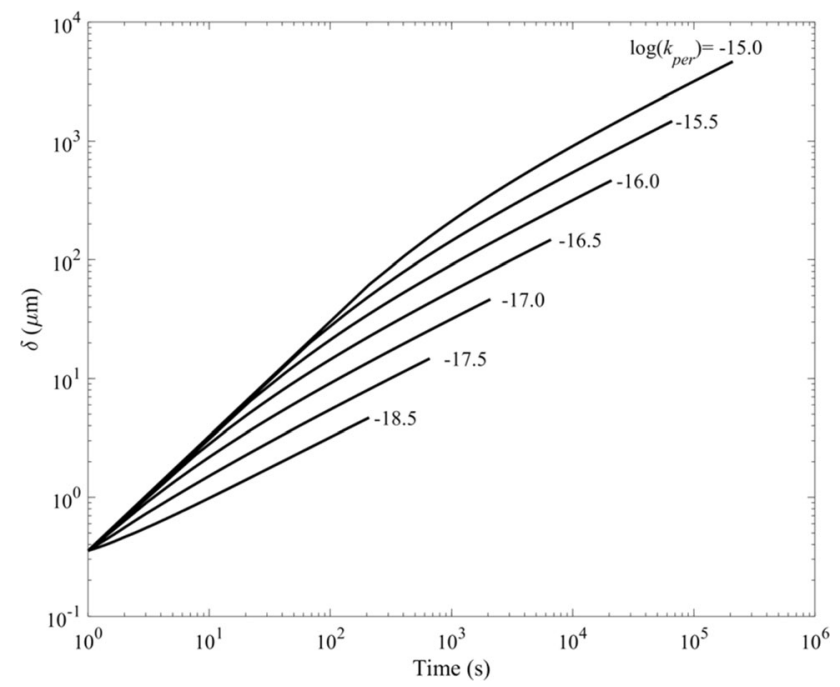

Fig. 11- Growth of the oxide layer, $\delta$, for different values of permeability at the meniscus level where $P=1 \mathrm{~atm}$.
Most previous studies have correlated velocity and turbulence fields to clogging in the form of deposition of suspended inclusions, i.e., the late stage of clogging. ${ }^{[14-16,18,29]}$ Figure 12(a) shows a schematic of the pressure field along the SEN. Assuming a single-phase flow, the pressure drop in the stopper gap can lead to negative pressure, i.e., cavitation may occur. ${ }^{[24]}$ If the SEN is not fully filled, then the pressure drop is smaller than that of the fully filled SEN. In practice, purging with argon bubbles enhances the pressure inside the SEN. The pressure increases with increasing distance from the stopper to reach atmospheric pressure around the meniscus level. Therefore, the pressure inside the SEN varies considerably. The growth of the oxide layer over time for a range of pressures ( 0.2 to $1.4 \mathrm{~atm})$ is plotted in Figure 12(b). Here, only the growth of early-stage clogging is evaluated. When the melt pressure was high and close to $P_{\mathrm{CO} \text {,eq }}=1.447 \mathrm{~atm}$, the oxide growth terminated in a few minutes. At lower pressures, the growth of the oxide layer lasted longer, and the growth rate (slope of the curve) was also larger.

Here, it is assumed that all the produced CO gas flows toward the steel melt and reacts with it. This assumption seems reasonable for the non-submerged part of the SEN because the pressure outside the SEN is higher than the interior pressure. It is also assumed that air is not sucked into the refractory pores because of this pressure difference, and $\mathrm{CO}$ is the only gaseous phase inside the SEN refractory. For the submerged part of the SEN, CO gas may flow in both directions, toward the inner and outer walls.

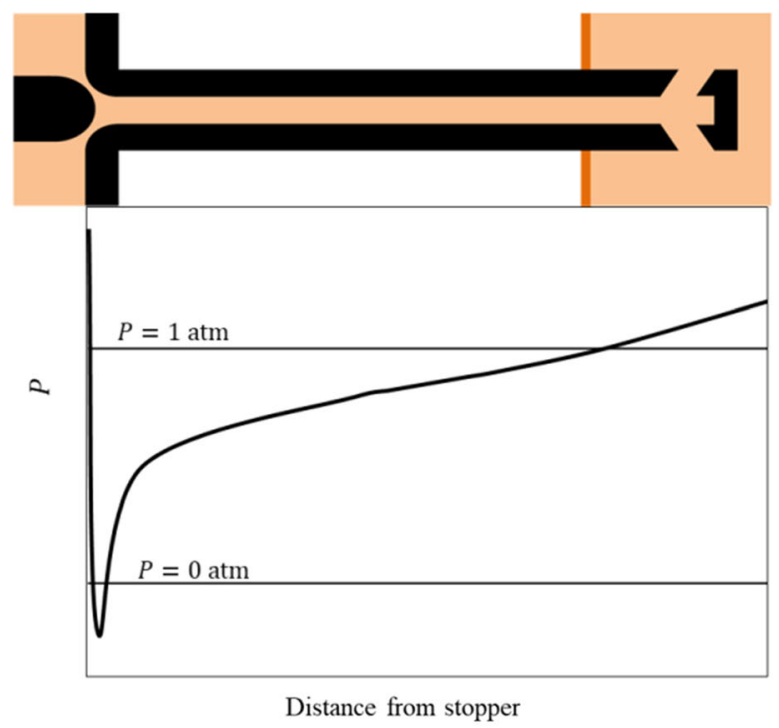

(a)

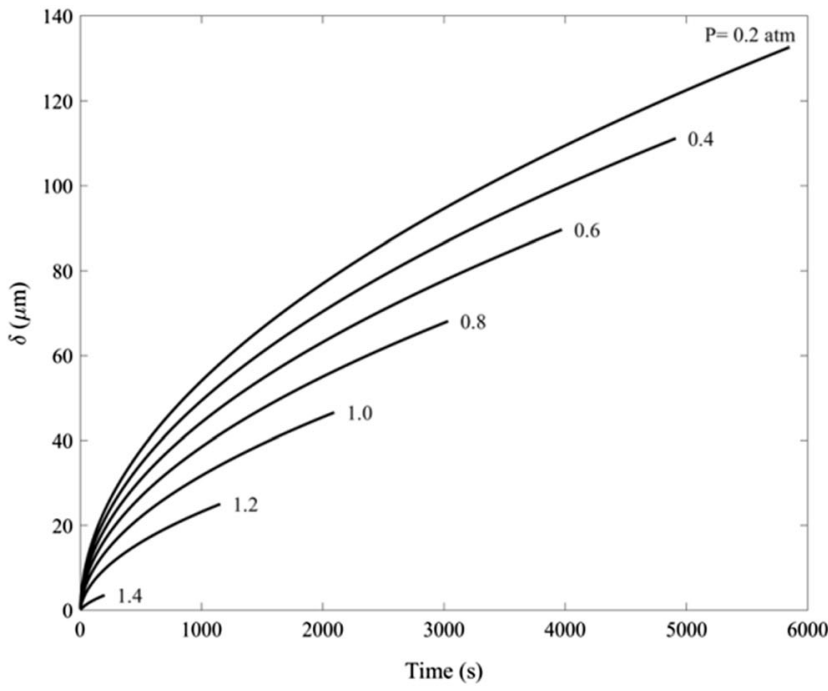

(b)

Fig. 12-(a) Schematic of the pressure distribution along the SEN when it is fully and partially filled. (b) Growth of the oxide layer and its dependence on $P$, assuming a constant permeability of the oxide layer $\left(k_{\text {per }}=1 \times 10^{-17} \mathrm{~m}^{2}\right)$. 


\section{CONCLUSIONS}

A mathematical formulation was proposed for the formation of an oxide layer during the early stage of clogging in the continuous casting of Ti-ULC steel. It was implemented as a sub-model in a combined clogging model, which was previously developed by the current authors for the transient growth of clogs via NMI deposition. In this sub-model, the melt pressure and composition of the SEN refractory are considered to calculate the growth rate of the oxide layer. The early stage of clogging, controlled by melt-refractory reactions, prepares the surface for the deposition of suspended NMIs during the late stage of clogging. The rate of NMI deposition is, in turn, controlled by turbulent melt flow. Therefore, the combined model considers the fluid dynamics, thermodynamics, and kinetics of the melt in a transient simulation of clogging. Moreover, this model correlates pressure in addition to velocity and turbulence to clogging tendency, which provides a more comprehensive tool for evaluating clogging during the continuous casting of Ti-ULC steel. The growth of the oxide layer in the early stage of clogging terminated owing to the enhanced pressure on the SEN refractory. NMI deposition can lead to an earlier termination of the growth of the oxide layer. The termination time of the early stage is also dependent on the melt pressure and permeability of the oxide layer. The pressure can be obtained from a CFD calculation of the flow in the SEN, but the permeability of the oxide layer must be obtained via experimental measurements.

\section{ACKNOWLEDGMENTS}

The authors gratefully acknowledge the funding support of K1-MET GmbH, metallurgical competence center. The research program of the K1-MET competence center is supported by COMET (Competence Center for Excellent Technologies), the Austrian program for competence centers. COMET is funded by the Federal Ministry for Climate Action, Environment, Energy, Mobility, Innovation, and Technology; the Federal Ministry for Digital and Economic Affairs; the Federal States of Upper Austria, Tyrol, and Styria; and the Styrian Business Promotion Agency (SFG). In addition to the public funding from COMET, this research project was partially financed by scientific partners (Montanuniversität Leoben and Johannes Kepler University Linz) and industrial partners (voestalpine Stahl Linz GmbH, voestalpine Stahl Donawitz GmbH, and RHI Magnesita $\mathrm{GmbH}$ ).

\section{CONFLICT OF INTEREST}

On behalf of all authors, the corresponding author states that there is no conflict of interest.

\section{FUNDING}

Open access funding provided by Montanuniversität Leoben.

\section{OPEN ACCESS}

This article is licensed under a Creative Commons Attribution 4.0 International License, which permits use, sharing, adaptation, distribution and reproduction in any medium or format, as long as you give appropriate credit to the original author(s) and the source, provide a link to the Creative Commons licence, and indicate if changes were made. The images or other third party material in this article are included in the article's Creative Commons licence, unless indicated otherwise in a credit line to the material. If material is not included in the article's Creative Commons licence and your intended use is not permitted by statutory regulation or exceeds the permitted use, you will need to obtain permission directly from the copyright holder. To view a copy of this licence, visit http://creat ivecommons.org/licenses/by $/ 4.0 /$.

\section{REFERENCES}

1. J.V. Barbosa, T.M.F. de Melo, and D.B. Santos: J. Mater. Res. Technol., 2020, vol. 9, pp. 2810-17.

2. K. Sasai and Y. Mizukami: ISIJ Int., 1994, vol. 34, pp. 802-09.

3. K. Sasai and Y. Mizukami: ISIJ Int., 1995, vol. 35, pp. 26-33.

4. S. Rödl, H. Schuster, S. Ekerot, G. Xia, N. Veneri, F. Ferro, S. Baragiola, P. Rossi, S. Fera, V. Colla, and et al.: New Strategies for Clogging Prevention for Improved Productivity and Steel Quality, 2012.

5. H. Cui, Y. Bao, M. Wang, and W. Wu: Int. J. Miner. Metall. Mater., 2010, vol. 17, pp. 154-58.

6. S.N. Singh: Metall. Trans., 1974, vol. 5, pp. 2165-78.

7. M. Kishimoto, K. Mori, and Y. Kawai: J. Jpn. Inst. Met., 1984, vol. 48, pp. 413-17.

8. A. Karasangabo and C. Bernhard: J. Adhes. Sci. Technol., 2012, vol. 26 , pp. $1141-56$.

9. S. Basu, S.K. Choudhary, and N.U. Girase: ISIJ Int., 2004, vol. 44, pp. 1653-60.

10. J.-H. Lee, M.-H. Kang, S.-K. Kim, and Y.-B. Kang: ISIJ Int., 2018, vol. 58 , pp. $1257-66$.

11. P. Dorrer, S.K. Michelic, C. Bernhard, A. Penz, and R. Rössler: Steel Res. Int., 2019, vol. 90, p. 1800635.

12. Y. Vermeulen, B. Coletti, B. Blanpain, P. Wollants, and J. Vleugels: ISIJ Int., 2002, vol. 42, pp. 1234-40.

13. Y. Miki, H. Kitaoka, T. Sakuraya, and T. Fujii: ISIJ Int., 1992, vol. 32, pp. 142-49.

14. L. Zhang, Y. Wang, and X. Zuo: Metall. Mater. Trans. B, 2008, vol. 39B, pp. 534-50.

15. H. Barati, M. Wu, A. Kharicha, and A. Ludwig: Powder Technol., 2018, vol. 329, pp. 181-98.

16. H. Barati, M. Wu, T. Holzmann, A. Kharicha, and A. Ludwig: in CFD Modeling and Simulation in Materials Processing 2018, L. Nastac, K. Pericleous, A.S. Sabau, L. Zhang, and B.G. Thomas, eds., Springer International Publishing, Cham, 2018, pp. 149-58.

17. D. Janis, A. Karasev, R. Inoue, and P.G. Jönsson: steel ResInt., 2015, vol. 86, pp. 1271-78.

18. H. Barati, M. Wu, A. Kharicha, and A. Ludwig: Metall. Mater. Trans. B, 2019, vol. 50, pp. 1428-43. 
19. H. Barati, M. Wu, A. Kharicha, and A. Ludwig: Steel Res. Int., 2020, vol. 91, p. 2000230.

20. Y.-B. Kang and J.-H. Lee: ISIJ Int., 2017, vol. 57, pp. 1665-67.

21. J.-H. Lee, M.-H. Kang, S.-K. Kim, J. Kim, M.-S. Kim, and Y.-B. Kang: ISIJ Int., 2019, vol. 59, pp. 749-58.

22. J.-H. Lee and Y.-B. Kang: ISIJ Int., 2020, vol. 60, pp. 258-66.

23. J.-H. Lee and Y.-B. Kang: ISIJ Int., 2020, vol. 60, pp. 426-35.

24. M. Thumfart and M. Javurek: Steel Res. Int., 2015, vol. 86, pp. 25-32.

25. B.G. Thomas: Steel Res. Int., 2018, vol. 89, p. 1700312.

26. D. Yang, W. Wang, W. Chen, X. Tan, and L. Wang: J. Rock Mech. Geotech. Eng., 2019, vol. 11, pp. 263-76.
27. L. Zhang and W. Pluschkell: Ironmak. Steelmak., 2003, vol. 30, pp. 106-10.

28. M. Suzuki, Y. Yamaoka, N. Kubo, and M. Suzuki: ISIJ Int., 2002, vol. 42, pp. 248-56.

29. P. Ni, L.T.I. Jonsson, M. Ersson, and P.G. Jönsson: Int. J. Multiphase Flow, 2014, vol. 62, pp. 152-60.

Publisher's Note Springer Nature remains neutral with regard to jurisdictional claims in published maps and institutional affiliations. 